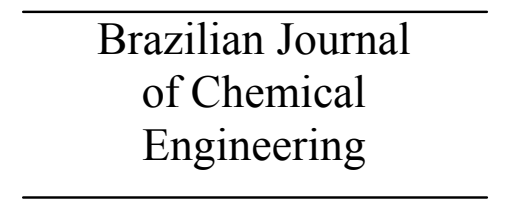

ISSN 0104-6632

Printed in Brazil

www.abeq.org.br/bjche

Vol. 28, No. 01, pp. 95 - 99, January - March, 2011

\title{
EXPERIMENTAL AND THEORETICAL RESEARCH ON CATALYTIC SYNTHESIS OF THIOPHENE FROM FURAN AND $\mathrm{H}_{2} \mathrm{~S}$
}

\author{
Hu Song-Qing ${ }^{1 *}$, Yuan Jian-Ye ${ }^{2}$, Shi Xin ${ }^{3}$, Guo Ai-Ling ${ }^{1}$ and Hu Jian-Chun ${ }^{4}$ \\ ${ }^{1}$ College of Physics Science and Technology, China University of Petroleum, Dongying Shandong, PR China. \\ *Current address: College of Physics Science and Technology, Phone: +86 13906474301, Fax: 0546 8397900, \\ China University of Petroleum, Postal Code: 257061, Dongying Shandong, PR China. \\ E-mail: ccupc@upc.edu.cn \\ ${ }^{2}$ Sinopec Jiangsu Oilfield Construction Section Algeria Pipeline Project, Yangzhou Jiangsu, PR China. \\ ${ }^{3}$ China Petrochemical Corporation Northwest Oilfield Branch, Xinjiang, PR China. \\ ${ }^{4}$ China Petroleum Pipeline Bureau, Langfang, PR China.
}

(Submitted: July 17, 2010 ; Revised: September 7, 2010 ; Accepted: October 18, 2010)

\begin{abstract}
The yield of thiophene from furan and $\mathrm{H}_{2} \mathrm{~S}$ was investigated using selected catalyst carriers (alumina, active carbon and silica gel) and active ingredients (silicotungstic, phosphomolybdic and phosphotungstic acids) to obtain the optimized synthesis parameters. The experimental results indicated that the yield of thiophene reached a maximum when the supported catalyst was alumina and the active ingredient was phosphotungstic acid. Furthermore, the reaction mechanism of the optimized reactive system was studied by the density functional theory (DFT) method. The calculated energy profile indicated that there were four transition states in the reaction process.

Keywords: Furan; Thiophene synthesis; Supported catalyst; Density functional theory.
\end{abstract}

\section{INTRODUCTION}

Thiophene is an important heterocyclic organic material. It is mainly used in sensitive materials, precursors for making pharmaceuticals, additives of photoluminescent materials, pigments and herbicides, etc. (Rivers et al., 2002; Perepichka et al., 2005; Barbarella et al., 2005; Barbarella et al., 2005). In addition, it is also adopted as a raw material and intermediate in the chemical industry (Zhang et al., 2008).

The synthesis and application of thiophenes have been thoroughly studied (Navacchia et al., 2008; Melucci et al., 2007; Zekai et al., 2008). The methods of synthesizing thiophene include the reactions of ring-closure and isomerization of the 5membered ring ( $\mathrm{Li}$ et al., 2008). The ring-closure reaction was a general route to synthesize thiophene in the past decades. For example, alkanes and hydrogen sulfide have been used as raw material for obtaining thiophene through the ring-closure reaction, but the yield of thiophene is rather low and there is no efficient method to improve it (Voronkov et al., 1981). In contrast to the ring-closure reaction, the isomerization reaction has the advantages of high yield and low cost (Southward et al., 1998). Many researches have indicated that the catalyst plays an important role in the synthesis of thiophene. The catalyst can induce the chemical reaction and improve the yield of target product. In the isomerization reactions between furan and $\mathrm{H}_{2} \mathrm{~S}$, the catalytic reaction using supported catalysts (active ingredient loaded on the surface of a carrier) drew more attention because of the high yield and high purity of the products. However, the high cost of furan prohibited the widespread use of this method in

*To whom correspondence should be addressed 
the past decades (Southward et al., 1998). With the development of industrial technology, the cost of furan has been greatly reduced in recent years. Moreover, the reaction can utilize the waste $\mathrm{H}_{2} \mathrm{~S}$ gas produced in the chemical industry. Therefore, this method is being used again to produce thiophene.

The literature on the optimization of the synthesis parameters and related mechanism for this reaction are scarce (Li et al., 2008). In this paper, the yields of thiophene were investigated to obtain optimized synthesis parameters. The supported catalysts consisted of several selected catalyst carriers and active ingredients. Furthermore, the reaction mechanism of the optimized reactive system was studied by the DFT method. Our experimental studies provide important guidance for increasing the yield. The following theoretical study was helpful for understanding the reaction mechanism and may serve as a reference for analyzing similar reaction mechanism.

\section{EXPERIMENTAL}

Alumina, activated carbon and silica gel have typically been used as carriers in the synthesis of thiophene ( $\mathrm{Li}$ et al., 2008; Li et al., 2009). Therefore, these three carriers were selected in our experiments to study their influence on the yield of thiophene.

\section{Carrier Pretreatment}

Three selected carriers were pretreated to ensure the best catalytic effect. As for the alumina carrier, it was obtained via the thermal treatment of pseudoboehmite by the following processes. The pseudoboehmite powder $\left(\mathrm{AlOOH} . \mathrm{nH}_{2} \mathrm{O}, \mathrm{n}=0.08 \sim 0.62\right)$ was mixed with dilute nitric acid $(2 \mathrm{wt} \%)$ and extruded into thin cylinders with a diameter of 3.0 $\mathrm{mm}$. The sample was dried at $110^{\circ} \mathrm{C}$ for $12 \mathrm{~h}$ and then calcined at $550^{\circ} \mathrm{C}$ for $5 \mathrm{~h}$. After that, the pseudo-boehmite was dehydrated to form alumina. As for activated carbon, it was immersed in dilute nitric acid ( $2 \mathrm{wt} \%$ ) for $4 \sim 5 \mathrm{~h}$ to remove the ash and alkaline matter absorbed onto its surface and then washed repeatedly with deionized water. Finally, it was dried at $120^{\circ} \mathrm{C}$ for $8 \mathrm{~h}$. As for silica gel $\left(\mathrm{xSiO}_{2} \cdot \mathrm{yH}_{2} \mathrm{O}\right)$, it was calcined at $500^{\circ} \mathrm{C}$ for $4 \mathrm{~h}$, immersed in deionized water for $12 \mathrm{~h}$, and then dried at $150 \sim 200^{\circ} \mathrm{C}$ for $6 \mathrm{~h}$.

\section{Loading of Active Intergradient on the Carriers}

First, the carriers were immersed in the solution containing the active intergradient for several hours.
Afterward, the immersed carriers were filtered and washed repeatedly with deionized water, and finally dried. Secondly, these carriers were activated under a certain temperature. The quantity of active ingredient loaded on the carrier could be controlled through adjusting the concentration of the active intergradient in solution and the immersion time.

\section{EXPERIMENTAL RESULTS}

\section{Selection of Optimized Experimental Parameters}

In order to improve the yield of thiophene, two critical experimental parameters, catalyst carrier and active ingredient, were systemically investigated.

\section{Catalyst Carrier}

With phosphotungstic acid as active ingredient, the yields of thiophene with the three catalyst carriers are shown in Fig.1. The yields of thiophene with the catalyst carriers of alumina, activated carbon and silica gel were $84.2 \%, 33.5 \%$ and $21.8 \%$, respectively. Thus, the yield with alumina was much higher than that with the other two catalyst carriers. The results indicated that alumina was the best carrier among the three selected catalyst carriers.

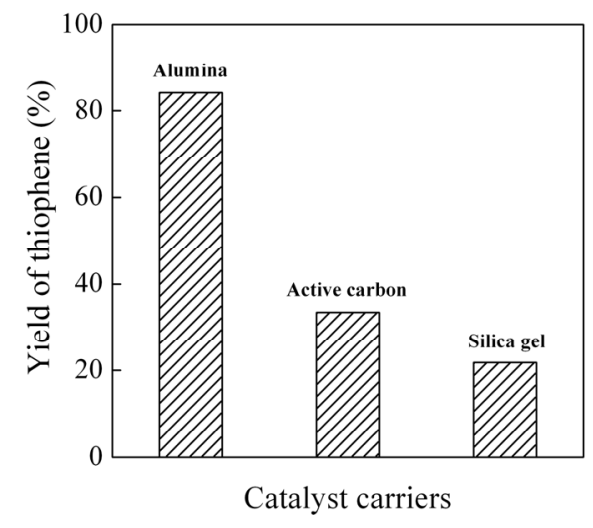

Figure 1: The yields of thiophene with phosphotungstic acid as active ingredient and the catalyst carriers of alumina, active carbon and silica gel.

\section{Active Ingredient}

Based on the optimization of catalyst carrier above, alumina was adopted as the carrier in the following experiments to optimize the active ingredient. Silicotungstic, phosphotungstic and phosphomolybdic acids have been commonly used as the active ingredients in the catalytic reaction (Brooker, et al., 
2009; Singh, et al., 2009). So, these three acids were selected as active ingredients for the catalytic reaction, and the alumina carrier was immersed in these three acid solutions with the same mass percentage of $2 \mathrm{wt} \%$. The yields of thiophene with the active ingredients of silicotungstic, phosphotungstic and phosphomolybdic acids are shown in Fig. 2. The yield of thiophene with phosphotungstic acid (84.2\%) was a little higher than that with silicotungstic acid (83.5\%) and phosphomolybdic acid (82.7\%).

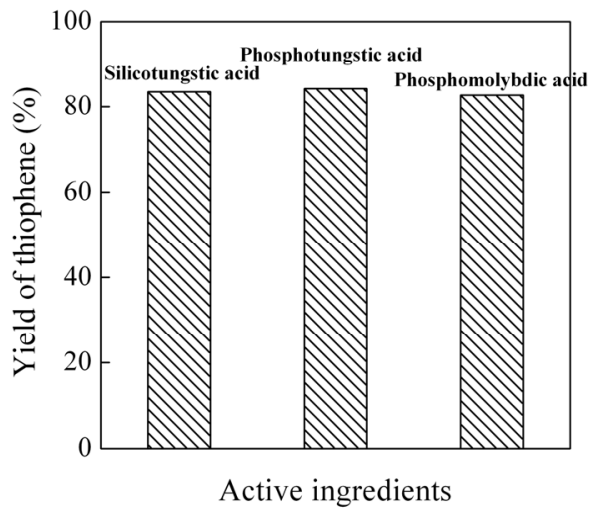

Figure 2: The yields of thiophene with the active ingredients of silicotungstic, phosphotungstic and phosphomolybdic acids with alumina as catalyst carrier

In addition, to evaluate the efficiency of the catalyst, the BET surface areas of alumina treated with the three different acids were investigated. The corresponding results are listed in Table 1. The alumina carrier activated by phosphotungstic acid has a relatively higher BET surface area. Thus, phosphotungstic acid was selected as the optimized active ingredient in the following studies.

Table 1: BET surface area of the alumina carrier activated by different catalysts

\begin{tabular}{|l|c|}
\hline $\begin{array}{l}\text { Carrier activated with different } \\
\text { acids }\end{array}$ & $\begin{array}{c}\text { BET surface area } \\
\left(\mathbf{m}^{2} / \mathbf{g}\right)\end{array}$ \\
\hline $\mathrm{Al}_{2} \mathrm{O}_{3} / 2 \mathrm{wt} \%$ silicotungstic acid & 243 \\
$\mathrm{Al}_{2} \mathrm{O}_{3} / 2 \mathrm{wt} \%$ phosphomolybdic acid & 237 \\
$\mathrm{Al}_{2} \mathrm{O}_{3} / 2 \mathrm{wt} \%$ phosphotungstic acid & 252 \\
\hline
\end{tabular}

\section{REACTION MECHANISM USING THE DFT METHOD}

Alumina and phosphotungstic acid were selected as the carrier and active ingredient, respectively, to investigate the reaction mechanism. Alumina was prepared by the dehydration of aluminum hydroxide.
Surfaces of $\mathrm{Al}_{2} \mathrm{O}_{3}$ consist of coordinatively unsaturated cations $\left(\mathrm{Al}^{3+}\right)$ and oxide $\left(\mathrm{O}^{2-}\right)$ ions. The surfaces are usually terminated by $\mathrm{OH}$ groups unless they are treated at elevated temperatures ( $\mathrm{Li}$ et al., 2008). In order to simplify the calculation, hydrafil was substituted by Structure 1, as shown in Fig. 3.

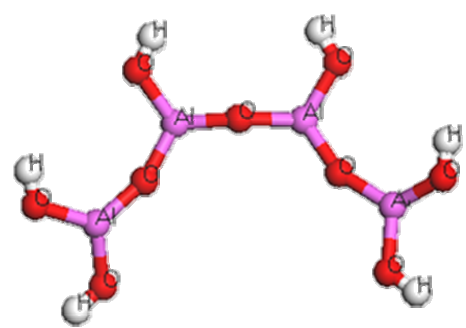

Structure 1

Figure 3: Schematic illustration of optimized molecular geometry of pseudo-boehmite

To investigate the reaction mechanism of thiophene, furan and hydrogen sulfide were the starting materials (Mashkina and Khairulina, 2008) and all of the reactive pathways were calculated by the self-consistent DFT method. The calculations were performed with the program package $\mathrm{DMol}^{3}$ in Material Studio 4.0. The exchange-correlation energy was calculated within the generalized gradient approximation (GGA) using the form of the functional RPBE proposed by Hammer et al. (Hammer et al., 1999). All of the atoms were treated with an all-electron basis set. The valence electron functions were expanded into a set of numerical atomic orbitals by a double-numerical basis with polarization functions (DNP). All computations were performed using spin-polarization with Fermi smearing of 0.005 Hartree. The transition state (TS) searches were performed at the same theoretical level via the completely linear synchronous transit (LST) with quadratic synchronous transit (QST) method (Halgren and Lipscomb, 1977). In this method, LST maximization was performed to obtain an approximate TS and then an energy minimization was conducted to obtain an optimized TS. The optimized TS was further optimized using QST maximization and another conjugated gradient minimization. This cycle was repeated until a stationary point was located. The convergence criterion of the TS searches was set as 0.01 Hartree $/ \AA$ for the root mean square of atomic forces. All the simulation work was carried out on Dell Pentium PC computer $(2.49 \mathrm{GHz}, 2.00 \mathrm{~GB})$.

All reaction processes including the thermal decomposition of aluminum hydroxide, the absorption of $\mathrm{H}_{2} \mathrm{~S}$ and furan, and the desorption of thiophene. 
First, alumina was formed by the thermal decomposition of aluminum hydroxide. Second, hydrogen sulfide absorbed on $\mathrm{Al}_{2} \mathrm{O}_{3}$. Then, the proton was transferred to an oxygen atom of $\mathrm{Al}_{2} \mathrm{O}_{3}$, and the $\mathrm{SH}^{-}$group adsorbed on the unsaturated cation $\left(\mathrm{Al}^{3+}\right)$. The anion $\mathrm{S}^{-}$was formed by the dehydration reaction between $\mathrm{OH}^{-}$and $\mathrm{SH}^{-}$. Furan would adsorb on the alumina surface through its $\mathrm{O}$ atom and combine with molecule 7 (see in Figure 4) via the formation of C-S and $\mathrm{Al}-\mathrm{O}$ bonds after the cleavage of the $\mathrm{C}-\mathrm{O}$ bond in furan. After that, thiophene would desorb from molecule 9 to finally form thiophene.

The corresponding energy changes in the whole reaction process are shown in Fig. 4 (a) and (b). There were four transition states in the reaction process including Ts1-2, Ts4-5, Ts5-6 and Ts8-9, with the energy barriers $242.1,116.6,150.4$, and $15.3 \mathrm{~kJ} / \mathrm{mol}$, respectively. The highest energy barrier $(242.1 \mathrm{~kJ} / \mathrm{mol})$ is in the first step in which a $\mathrm{H}_{2} \mathrm{O}$ molecule was formed.
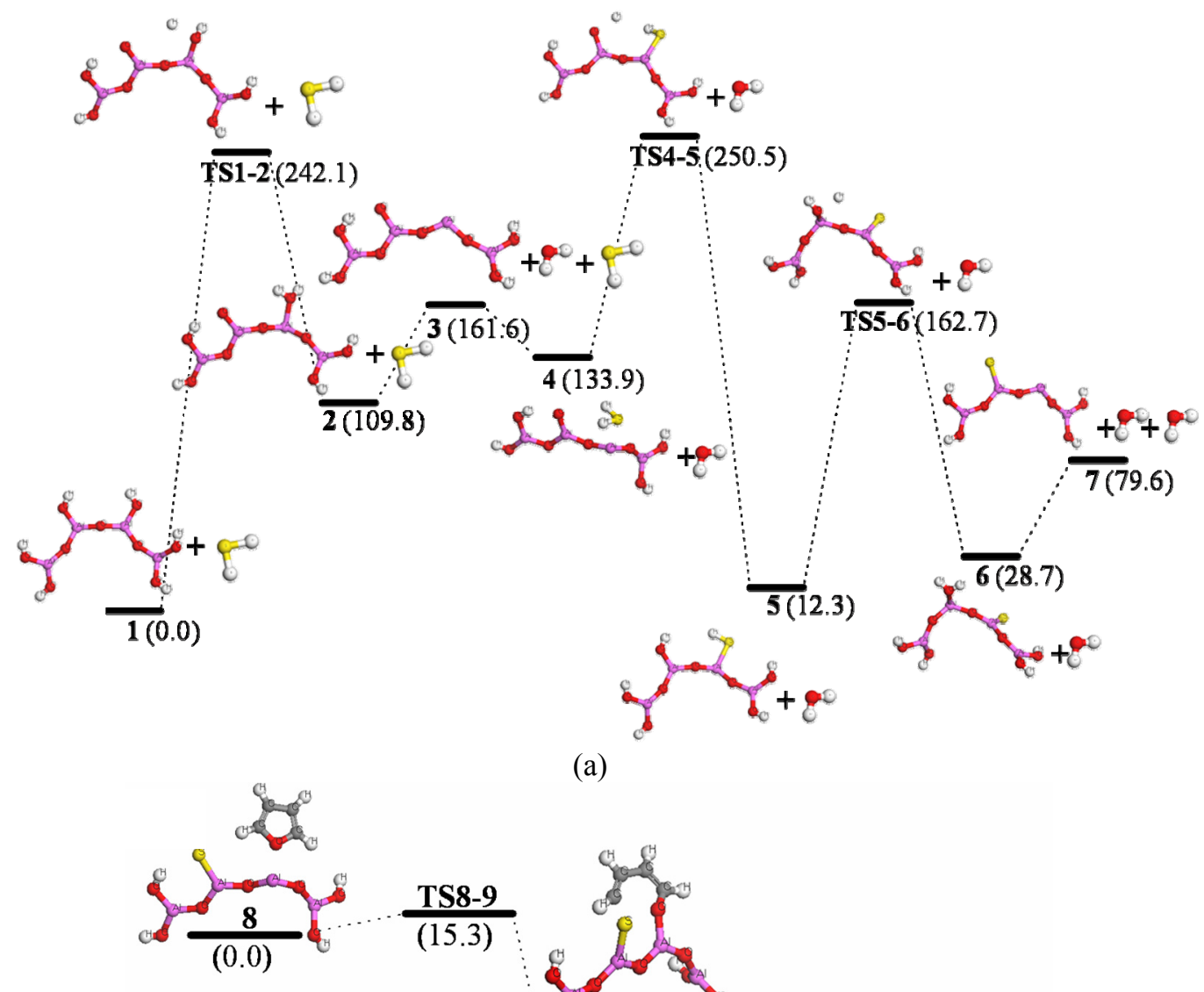

(a)
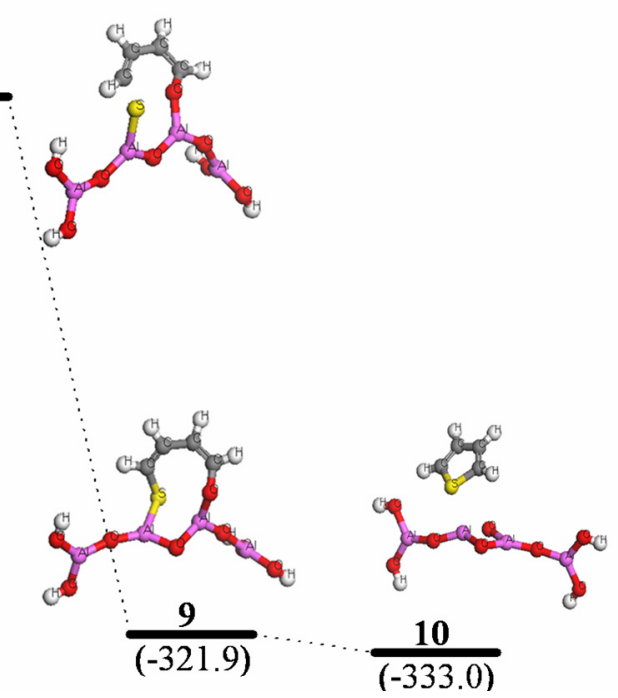

(b)

Figure 4: (a) Energy diagram ( $\mathrm{kJ} / \mathrm{mol})$ of the thermal decomposition of aluminum hydroxide and the absorption of $\mathrm{H}_{2} \mathrm{~S}$; (b) Energy diagram of the absorption of furan and the desorption of thiophene. 


\section{CONCLUSIONS}

The yield of thiophene was investigated using selected catalyst carriers (alumina, active carbon and silica gel) and active ingredients (silicotungstic, phosphomolybdic and phosphotungstic acids) to obtain the optimized synthesis parameters. The yield of thiophene reached a maximum when the supported catalyst was alumina and the active ingredient was phosphotungstic acid. The reaction mechanism of the optimized reaction system was studied by the density functional theory (DFT) method. The calculated energy indicated that there were four transition states in the reaction process (Ts1-2, Ts4-5, Ts5-6 and Ts8-9) and the energy barriers were $242.1,116.6,150.4$, and $15.3 \mathrm{~kJ} / \mathrm{mol}$, respectively.

\section{ACKNOWLEDGEMENTS}

The authors gratefully acknowledge China National Petroleum Corporation Innovation Fund (No. 2008D-5006-02-08) for financial support.

\section{REFERENCES}

Barbarella, G., Melucci, M. and Sotgiu, G., The versatile thiophene: An overview of recent research on thiophene-based materials. Adv. Mater, 17, 1581 (2005).

Barbarella, G., Favaretto, L., Zanelli, A., Gigli, G., Mazzeo, M., Anni, M., Bongini, A., V-shaped thiophene-based oligomers with improved electroluminescence properties. Adv. Funct. Mater, 15, 664 (2005).

Brooker, R. P., Baker, P., Kunz, H. R., Bonvile, L. J. and Parnas, R. Effects of silicotungstic acid addition to the electrodes of polymer electrolyte membrane fuel cell. J. Electrochem. Soc., 156, B1317-B1321 (2009).

Hammer, B., Hansen, L. B., Norskov, J. K., Improved adsorption energetics within densityfunctional theory using revised Perdew-BurkeErnzerhof functionals. Phys. Rev., B, 59, 7413 (1999).

Halgren, T. A. and Lipscomb, W. N., The synchronoustransit method for determining reaction pathways and locating molecular transition states. Chem. Phys. Lett., 49, 225 (1977).
Li, Q. F., Xu, Y. Q., Liu, C. G., Kim, J., Catalytic synthesis of thiophene from the reaction of furan and hydrogen sulfide. Catal. Lett., 122, No. 3-4, 354 (2008).

Li, Q. F., Chen, C. G., Kim, J. C., Catalytic synthesis of thiophene from the reaction of n-butanol and carbon disulfide over $\mathrm{K}_{2} \mathrm{CO}_{3}$-promoted $\mathrm{Cr}_{2} \mathrm{O}_{3} / \gamma$ alumina catalyst. Korean J. Chem. Eng., 26, 5763 (2009).

Melucci, M., Favaretto, L., Barbarella, G., Zanelli, A., Camaioni, N., Mazzeo, M., Gigli, G., Synthesis and optoelectronic properties of a red emitting branched polymer containing V-shaped oligothiophene-S,S-dioxides as repeating units. Tetrahedron, 63, 11386 (2007).

Navacchia, M. L., Melucci, M., Favaretto, L., Zanelli, A., Gazzano, M., Bongini, A., Barbarella, G., Alkylenesulfanyl-bridged Bithienyl cores for simultaneous tuning of electronic, filming, and thermal properties of oligothiophenes. Org. Lett., 10, 3665 (2008).

Perepichka, I. F., Perepichka, D. F., Meng, H. and Wudl, F., Light-emitting polythiophees. Adv. Mater., 17, No. 1, 2281 (2005).

Rivers, T. J., Hudson, T. W., Schmidt, C. E., Synthesis of a novel, biodegradable electrically conducting polymer for biomedical applications. Adv. Funct. Mater., 12, No. 1, 33 (2002).

Singh, P., Kumar, P., Katyal, A., Kalra, R., Dass, S. K., Prakash, S. and Chandra, R. Phosphotungstic acid: an efficient catalyst for the aqueous phase synthesis of bis-(4-hydroxycoumarin-3-yl)methanes. Catal. Lett., 134, No. 3-4, 303-308 (2009).

Southward, B. W. L., Fuller, L. S., Hutchings, G. J., Joyner, R. W. and Stewart, R. A. Novel catalysts for thiophene synthesis at lower temperatures. Chem. Commun., 5, No. 1, 241 (1998).

Southward, B. W. L., Fuller, L. S., Stewart, R. A., Hutchings, G. J., Joyner, R. W. and Stewart, R. A., Comments on the mechanism of the vapourphase catalytic synthesis of thiophenes. Catal. Lett., 55, 207-210 (1998).

Voronkov, M. G., Trofimov, B. A., Krjuchkov, V. V., Amosova, S. V., Skvortsov, J. M., Volkov, A. N., Malkina, A. G., Mnshy, R. Y., Method of producing thiophene. US: 4251666 (1981).

Zhang, Z. K., Niu, X. L., Liu, S. L., Zhu, X. X., Yu, H. W. and $\mathrm{Xu}, \mathrm{L}$. Y., The performance of HMCM-22 zeolite catalyst on the olefin alkylation thiophenic sulfur in gasoline. Catal. Commun., 9, No. 1, 60 (2008). 